\title{
Avaliação flexibilizada para alunos com necessidades educacionais especiais: uma prática pedagógica inclusiva
}

\author{
Flexbile evaluation for special needs students: \\ An inclusive pedagogical practice
}

\section{Evaluación flexible para estudiantes con necesidades educativas especiales: una práctica pedagógica inclusiva}

Rosana Glat ${ }^{1}$

https://orcid.org/0000-0002-0186-1342

Suzanli Estef²

https://orcid.org/0000-0003-3354-6598

\begin{abstract}
Resumo: Este ensaio analisa o processo de avaliação de alunos com necessidades educacionais especiais, no contexto da escola básica. A discussão tem como base dados obtidos em entrevistas semiestruturadas com professores e coordenadores pedagógicos do Ensino Fundamental II e Ensino Médio, de três escolas na Cidade do Rio de Janeiro. Esta temática é relevante pela complexidade de avaliar o desempenho acadêmico de alunos cujas demandas não podem ser atendidas por um sistema de ensino estruturado para a homogeneidade, baseado em um modelo de avaliação padronizado, classificatório e meritocrático. A análise dos dados revelou as possibilidades de favorecer a inclusão e aprendizagem a partir da flexibilização e individualização do ensino, desenvolvendo ações pedagógicas que proporcionem critérios e procedimentos avaliativos considerando as características próprias de cada aluno e que tenham como objetivo aprimorar o processo ensino aprendizagem. Palavras Chave: inclusão escolar. Avaliação. Alunos com necessidades educacionais especiais.
\end{abstract}

\begin{abstract}
This essay analyses the evaluation process of special needs students in the context of regular school. The discussion is based on data obtained in semi structure interviews with teachers and pedagogical coordinators of Middle and High School of three schools in the city of Rio de Janeiro. This theme is relevant in terms of the complexity of evaluate de academic achievement of students whose demands cannot be met by an education system structured towards homogeneity, based on a standardized, classifying and meritocratic evaluation model. Data analysis revealed the possibilities of favoring inclusion and learning by means of flexibility and individualization of teaching methods, developing pedagogical actions that provide evaluation criteria and procedures which consider the singular characteristics of each student, and that have as aim to improve the teaching-learning process.
\end{abstract}

\footnotetext{
I Doutora em Psicologia Social. Professora Titular do Programa de Pós-graduação em Educação da Universidade do Estado do Rio de Janeiro. E-mail: rosanaglat@gmail.com

2 Doutora em Educação. Professora de Educação Especial do Colégio de Aplicação da Universidade Federal do Rio de Janeiro. E-mail: suzanli_estef@hotmail.com
}

Olhar de professor, Ponta Grossa, v. 24, p. I-13, e-19708.096, 202 I.

Disponível em <https://revistas2.uepg.br/index.php/olhardeprofessor> 
Keywords: School inclusion. Evaluation. Special needs students.

Resumen: Este ensayo analiza el proceso de evaluación de estudiantes con neceidades educativas especiales, en el context de la escuela básica. La discusión se basa en datos obtenidos de entrevistas semiestructuradas con profesores y coordinadores pedagógicas de la Escuela Primaria II y Bachillerato, de tres escuelas de la ciudad de Rio de Janeiro. Este tema es relevante por la complejidade de evaluar el desempeño académico de los estudiantes cuyas demandas no pueden ser satisfechas por un sistema educativo estructurado de homogeneidad, basado en un modelo de ealuación estandarizado, clasificatorio y meritocrático. El análisis de datos reveló las posibilidades de favorecer la inclusion y ela aprendizaje desde la flexibilidad e individualización de la ensenãnza, desarrollando acciones pedagógicas que brinden criterios y procedimientos de evaluación considerando las características de casa alumno y que tengan como objetivo mejorar el proceso de ensenñanza-aprendizaje.

Palabras-clave: Inclusión escolar. Evaluación. Estudiantes con necesidades educativas especiales.

\section{Introdução}

Nas últimas décadas, seguindo diretrizes internacionais (UNESCO, 1994; ONU, 2007³, entre outras) a política de inclusão escolar de alunos com deficiências e outras condições atípicas de desenvolvimento vem gradativamente se estabelecendo em nosso país, atingindo tanto a rede pública quanto privada. Este direcionamento ficou marcado, sobretudo, a partir da promulgação da Política Nacional de Educação Especial na Perspectiva da Educação Inclusiva (BRASIL, 2008) que, entre outros aspectos, orienta os sistemas educacionais a estabelecer suporte da Educação Especial nas escolas de ensino comum, para receber todos os alunos. Essas determinações foram reforçadas em diversos marcos legais que se seguiram (BRASIL 2009; 201 la; 20l lb), destacando-se o Capítulo IV da Lei $n^{\circ}$ 13.146, conhecida como Lei da Inclusão - Estatuto da Pessoa com Deficiência (BRASIL, 20I5)

Entretanto, conforme apontam diversos estudos, a realidade educacional brasileira não atende aos quesitos promulgados pelas políticas e diretrizes. Apesar do significativo aumento das matrículas de estudantes público-alvo da Educação Especial (BRASIL, 2020), os sistemas de ensino ainda se deparam com dificuldades para transformar a estrutura organizacional e curricular de suas escolas e atender à diversidade do alunado que nelas ingressa (GLAT; PLETSCH, 20I I; MATOS; MENDES, 20 I4; KASSAR, REBELLO, OLIVEIRA, 2019; PLESCH; SOUZA, 202I).

A Educação Inclusiva tem como pressuposto básico que a escola esteja estruturada de forma a acolher e atender a todos os alunos. Mas para tal, como apontam Marin e Maretti (2014), é preciso priorizar práticas pedagógicas diferenciadas que propiciem uma escolarização efetiva para aqueles que apresentem diferenças significativas no seu processo de desenvolvimento e aprendizagem.

\footnotetext{
3 Trata-se da Convenção dos Direitos da Pessoa com Deficiência, cujo protocolo foi assinado na ONU em 2007, e sancionado no Brasil pelo Decreto 6949/2009.
} 
No contexto das adaptações currículo-pedagógicas que a escola contemporânea precisa contemplar para atender à diversidade, um dos maiores desafios é a avaliação de desempenho dos alunos. Por conta da predominante rígida organização seriada com conteúdo curricular préestabelecido, este processo, de modo geral, tem um caráter classificatório e eliminatório (aprovado ou reprovado). Pois, em última instância, o que, de fato, é valorizado na avaliação escolar é o produto (nota ou conceito) e não o processo de desenvolvimento acadêmico do aluno.

Tradicionalmente, a escola tem optado por realizar avaliações de maneira descontextualizada e limitadora, na qual de acordo com Luckesi (1995) a verificação da aprendizagem é preterida, uma vez que o dado é coletado de maneira acrítica e se encerra nele mesmo, isto é, após a informação reproduzida na prova e/ou trabalho o assunto é encerrado. A avaliação deve ir além do ato de verificar e classificar, pois um ensino baseado apenas no que já foi produzido, em detrimento às ações que poderiam ser realizadas pela escola, não favorecerá o processo de ensino e aprendizagem dos sujeitos com ou sem deficiência. (PLETCH; OLIVEIRA, 20I4, p.5-6)

Corroborando com as colocações dessas autoras, entendemos que para a efetivação da inclusão escolar é primordial se adotar uma perspectiva de flexibilização didática, com o olhar voltado para as características diferenciadas dos alunos. A ênfase na nota deveria ser minimizada, priorizandose $\circ$ processo ensino aprendizagem, considerando-se adaptações e flexibilizações nas práticas pedagógicas, nos conteúdos curriculares e nos instrumentos avaliativos (ESTEF, 2016).

Mais do que medir resultados através de testes e provas em momentos estanques e prédeterminados do calendário escolar, a avaliação é uma ação integrante do planejamento pedagógico e deve se constituir como um processo contínuo, envolvendo a revisão e redirecionamento das propostas curriculares e metodologias, visando apontar eventuais dificuldades e proporcionar avanços na aprendizagem dos alunos.

Conforme ressalta Canen (2005, p. 18), a avaliação escolar processual "busca levantar dados no decorrer do processo, por intermédio de atividades e instrumentos diversificados, que visam avaliar aspectos plurais pelos quais se dá a aprendizagem. A avaliação tem como propósito, o crescimento de alunos e de instituições"

Pode-se dizer que a avaliação é o "carro chefe" da dinâmica escolar, pois é através desse processo que o sucesso ou o fracasso acadêmico dos estudantes é sancionado. A avaliação define quem são os "bons" alunos e aqueles que "não apreendem o conteúdo", mede graus de conhecimento ou de domínio, fixa patamares e níveis, e distingue aqueles que "são capazes" e os que "não são capazes" de progressão no universo escolar. Como lembra Perrenoud (1999, p. 19), "o êxito e o fracasso são 
realidades socialmente construídas, tanto em sua definição global quanto na atribuição de um valor a cada aluno, em diversas fases da trajetória escolar através das práticas de avaliação".

Neste escopo, é importante ressaltar que o modelo de avaliação adotado por uma escola está diretamente articulado à sua concepção curricular e ao seu projeto pedagógico, sendo também resultante, direta e indiretamente, da formação dos professores e das políticas educacionais vigentes. Avaliação é um processo complexo, abrangendo e perpassando todo o sistema educacional. Vinculada às ações pedagógicas de ensino, não pode ser analisada paralelamente às finalidades e propostas curriculares adotadas no cotidiano escolar.

Ponderando sobre o atual cenário, em que as políticas de inclusão estão sendo implementadas em estruturas organizacionais e curriculares estratificadas, o presente artigo propõe uma reflexão sobre o processo de avaliação de alunos com necessidades educacionais especiais, no contexto da escola básica. A discussão terá como base depoimentos prestados, em uma pesquisa de campo, por 06 professores e 06 coordenadores de três escolas, duas privadas e uma pública, localizadas na Cidade do Rio de Janeiro 4 .

\section{Avaliação flexibilizada no contexto da diferenciação de ensino}

Independente de características individuais, que facilitem ou dificultem a aprendizagem, o resultado da avaliação do desempenho escolar de um aluno é diretamente afetado pelas práticas pedagógicas às quais ele foi submetido. Ou seja, pela escolha de determinadas metodologias, recursos e materiais didáticos, bem como dos próprios instrumentos e procedimentos de avaliação, que podem favorecer ou não esse processo.

Como mencionado, para efetivação de uma educação inclusiva, que considere a diversidade do alunado, a escola precisa adotar uma postura transformadora, ressignificando suas concepções em relação ao currículo, ao projeto político pedagógico e, consequentemente, às práticas de ensino e avaliação. Conforme colocado pela Coordenadora de Ações Inclusivas de uma das instituições investigadas:

Avaliação implica nas escolhas didáticas que eu vou fazer; nas escolhas pedagógicas e dos conteúdos que eu vou trabalhar e como eu vou entender esse aluno dentro de um contexto de uma escola seriada, de uma escola que no final do ano tem que aprovar ou reprovar.

\footnotetext{
4 Trata-se de um recorte de uma pesquisa tipo etnográfica, envolvendo, além de entrevistas semiestruturadas com os educadores, análise documental e observações de campo (ESTEF, 202I).
}

Olhar de professor, Ponta Grossa, v. 24, p. I-13, e-19708.096, 2021.

Disponível em <https://revistas2.uepg.br/index.php/olhardeprofessor> 
Visando transpor, em alguma medida, o paradoxo de trabalhar com a diversidade em uma organização curricular com objetivos pré-determinados propõe-se que a avaliação ocorra consecutivamente e não em momentos estanques, em situações isoladas de realização de provas e testes. Nesta perspectiva, a avaliação não se limita apenas em medir quantitativamente o conhecimento adquirido, mas torna-se elemento integrante do processo de construção do aprendizado. Nas palavras da Coordenadora Pedagógica de uma das escolas:

O que é avaliação? A avaliação se dá diariamente e a gente tinha que encontrar uma forma de não ter só esse momento estanque de prova, trabalho, de teste, mas assim de fazer [...] aquela coisa de acompanhamento diário. Que percebe como ele avançou! Se ele tem um resultado ruim numa prova isso não faz diferença, porque eu sei que aquele aluno, na verdade aquele resultado foi mascarado, ele pode ter ficado nervoso, estava num mau momento, a forma como eu coloquei a questão foi uma forma complicada com um vocabulário muito rico do que normalmente eu uso em sala de aula e isso pode interferir.

Nesse sentido, a questão essencial não é qual a nota ou conceito que o aluno deve receber, e sim, considerar as atividades avaliativas como um dos componentes da prática pedagógica, porém não o fator determinante de aferição do grau de aprendizagem do estudante. O olhar contínuo, no cotidiano escolar, deve ser um fator integrante à avaliação conforme os relatos a seguir:

Não é somente o momento de prova, o olhar dever ser processual, porque fazemos uma atividade em grupo e avaliamos propomos uma tarefa de grupo e pedimos feedback naquela hora, mandamos um menino para o quadro pra explicar como é que ele fez [...] (professor de Matemática - Ensino Fundamental II)

[...] o momento avaliativo tem um objetivo muito claro que é saber o que a criança realiza sozinha. Mas ele não é o único instrumento de avaliação, toda a produção que a criança faz, a postura dela de estudante, o compromisso com a escola, enfim...tudo isso compõe a nota. (Professora de Língua Portuguesa - Ensino Fundamental II)

Esta mesma perspectiva é reforçada nos Parâmetros Curriculares Nacionais (BRASIL, 1997, p.55), onde é ressaltado que o processo de avaliação deve acontecer de maneira "[...] contínua $e$ sistematicamente por meio da interpretação qualitativa do conhecimento construído pelo aluno". Isto significa que uma avaliação com ênfase apenas em conteúdos isolados não é suficiente. A avaliação como processo caracteriza-se pelo acompanhamento permanente do aprimoramento acadêmico dos estudantes, visando o seu desenvolvimento global. Logo, não pode ser só uma medida quantitativa de aspectos isolados de conteúdos curriculares.

Em uma tentativa de romper com o modelo tradicional de avaliação classificatória para se adequar à perspectiva inclusiva, várias escolas, como as participantes da referida pesquisa, têm buscado adotar práticas flexibilizadas, tais como adaptações nos instrumentos avaliativos, ampliação do tempo e/ou modificação do espaço para realização das provas e testes, entre outras. 
Esses meninos precisam de momentos para fazer as atividades avaliativas em outro espaço, porque eles precisam de uma outra concentração, de outro tempo. Buscase atender a eles naquilo que eles necessitam[...] (Professora de Língua Portuguesa, Ensino Fundamental II)

Embora essas práticas já sejam adotadas em grande parte das escolas inclusivas, foi interessante observar que a maioria dos educadores entrevistados consideram o modelo de avaliação flexibilizada como uma estratégia de individualização do ensino. Segundo a fala de uma professora de Matemática, do Ensino Médio:

Só que o que se avalia com ele, é o processo dele, em relação ao grupo, mas é mais dele". Esta mesma postura foi reiterada por uma Coordenadora Pedagógica "[...] ela acontece de forma processual como deve ser o aluno avaliado; claro, que em relação ao ano de escolaridade, mas é o crescimento dele.

Os relatos dos professores a seguir reforçam este argumento

Então, o conceito de número para ele não era algo ainda consolidado. Então, enquanto a turma já operava com milhares, ele ainda operava com centena. (Professor de Matemática - Ensino Fundamental II)

[...] todo instrumento, como todos os outros, a gente faz uma adaptação, a gente vê - que é possível que ele possa fazer dentro daquilo, dentro daquilo que nós planejamos para ele. (Professora de Língua Portuguesa - Ensino Fundamental II)

Então, dentro daquela proposta para ele, nós fazemos a adaptação daquele instrumento. Por exemplo, a leitura com inferências, então ele faz outro texto com outras questões mais objetivas, porque para ele a metáfora é mais difícil, palavras que ele precisa inferir, relacionar num sentido. (Professor de Língua Portuguesa - Ensino Médio)

Indubitavelmente, um dos pontos mais desafiadores na adoção de uma metodologia de flexibilização curricular ${ }^{5}$ é o risco de se individualizar o processo ensino aprendizagem, de tal modo, ao ponto de separar o aluno do contexto acadêmico do seu grupo de referência ou ano de escolarização. Mesmo reconhecendo-se que "adaptações valorizam aquele sujeito, aquele potencial que ele naquele momento está realizando" (Professor de Matemática- Ensino Fundamental II), os anos ou séries escolares são organizados com base em conjunto de conteúdos programáticos que precisam ser minimamente cumpridos para promoção à etapa seguinte.

Em outras palavras, é preciso encontrar um equilíbrio entre flexibilizar a proposta pedagógica, oportunizando didáticas que atendam às necessidades de aprendizagem do aluno, sem que essas adaptações individualizadas sejam desvinculadas da matriz curricular vigente para o restante da turma.

\footnotetext{
${ }^{5}$ Entendemos currículo em uma concepção ampla, incluindo conteúdos programáticos, práticas pedagógicas de ensino e de avaliação.
}

Olhar de professor, Ponta Grossa, v. 24, p. I-13, e-19708.096, 2021.

Disponível em <https://revistas2.uepg.br/index.php/olhardeprofessor> 
Você tem que partir do pressuposto daquilo que está previsto para aquela adequação. E é muito importante que essa adequação tente, na medida do possível, trabalhar aproximações dos pares que ele tem, porque senão a gente segrega de novo e isso é uma grande dificuldade.

[...] quanto mais avançado vai se dando esses anos de escolaridade mais de significativo, provavelmente, esse currículo tem de diferenciação. E aí o que a gente tem que cuidar com muita atenção é para não cair na esparrela de incluir para excluir depois... então é um pouco disso. (Coordenadora de Ações Inclusivas)

Apesar da complexidade de sua implementação, um modelo de avaliação flexibilizada propicia aos alunos com necessidades educacionais especiais melhores oportunidades de expressar seus aprendizados. Neste sentido, a avaliação escolar é vista como uma ação pedagógica processual e formativa que analisa o desempenho do aluno em relação ao seu desenvolvimento individual, sobressaindo aspectos qualitativos que orientem as práticas pedagógicas do professor (BRASIL, 2008).

Dessa forma, a equipe escolar deve assumir uma postura de atuação dinâmica, utilizando um modelo de avaliação processual que lhe permita identificar as necessidades atuais de aprendizagem do aluno, bem como suas áreas em desenvolvimento. Tendo, no entanto, a cautela de não diferenciar a proposta curricular traçada para ele a ponto de deixá-lo à margem do sistema educacional (ESTEF, 2016).

Conforme discutido, para além de medir o desempenho acadêmico do aluno, a avaliação concebida como um processo contínuo, cumulativo e diagnóstico, redimensiona a ação pedagógica e permite produzir novas estratégias que favoreçam a aprendizagem de todos os estudantes. Certamente, este não é um processo simples de ser implementado, conforme destaca um dos entrevistados:

[...] avaliação deve ser processual, mas não é tão simples de ser feito [...] que você faça alguns registros durante esse processo porque no dia tal ele fez assim, mas agora ele fez com tanta autonomia. Gente! O que houve? Há dois dias atrás ele não conseguia elaborar com essa autonomia e hoje ele elaborou. Quais são as variáveis? É o ambiente que é mais tranquilo? É a relação um para um? Ele pode ler em voz alta sem ter ninguém que interferisse? O que fizemos para colaborar com essa mudança? (Professor de Língua Portuguesa, Ensino Médio).

Talvez, devido à complexidade de se instaurar um modelo de avaliação processual flexibilizado, a maioria das escolas continua mantendo práticas pedagógicas padronizadas, sem levar em consideração a especificidade dos estudantes. Santos e Martins (2015) analisando a dinâmica de 02 escolas, consideradas inclusivas, encontraram pouca inovação em termos de recursos pedagógicos diversificados para possibilitar a apropriação dos conhecimentos e promoção para o ano seguinte. 
Conforme colocado no início deste texto, não se pode refletir sobre avaliação do desempenho escolar desvinculada de uma discussão mais ampla sobre a dinâmica do processo ensino aprendizagem como um todo. A Educação Inclusiva requer um conjunto de flexibilizações pedagógicas que atendam às demandas diferenciadas dos alunos no processo de escolarização (TOMLINSON, 2008; ZERBATO; MENDES, 2018). Vale ressaltar, porém, que diferenciação não se refere a um empobrecimento ou eliminação de conteúdos curriculares, mas sim à revisão de estratégias e recursos pedagógicos. Portanto,

Não se trata de elaborar um outro currículo e sim trabalhar com o que for adotado, fazendo nele os ajustes necessários (flexibilização nos objetivos, conteúdos, metodologia de ensino, temporalidade, e nas práticas de avaliação da aprendizagem) de modo a oferecer a todos a verdadeira igualdade de oportunidades para construir conhecimento (CARVALHO, 2008, p. 105).

Esta é a ideia subjacente ao conceito de Desenho Universal para Aprendizagem (DUA) que consiste na elaboração de práticas pedagógicas flexibilizadas e estratégias de acessibilidade ao currículo para todos os estudantes (ZERBATO; MENDES, 2018; MASCARO; REDIG, 202I). Pensado para atender às demandas diversificadas do universo escolar atual, um planejamento baseado no DUA oferece atendimento individualizado aos estudantes com necessidades educacionais especiais, porém inserido na programação geral da turma. Não se trata, exatamente de adaptar o currículo, mas, nas palavras de Carvalho (2008, p. 32), "apresentar informações e conteúdo de formas diferentes; flexibilizar as formas que os alunos podem expressar o que sabem; estimular o interesse e a motivação para a aprendizagem".

Assim, na medida em que o olhar pedagógico se flexibiliza nas práticas de ensino e de avaliação para atender às especificidades daqueles alunos que necessitam uma maior individualização, o processo ensino aprendizagem como um todo é aprimorado. Conforme comentou uma professora:

[...] avaliação tem, é claro, esse padrão de olhar as particularidades, de olhar as individualidades, de olhar os contextos individuais e os contextos daquela turma. $\mathrm{E}$ que eu contemplo a isso os alunos com necessidades especiais e ganha, com isso, toda a turma porque eu também passo a olhar toda a turma de uma maneira diferente. (Professora Língua Portuguesa - Ensino Fundamental II)

Embora não se referindo, especificadamente, ao DUA, diversos autores vêm questionando o modelo de homogeneização curricular e suas implicações no processo de avaliação da aprendizagem. Nas palavras de Pimentel (I994 apud OLIVEIRA; VALENTIN; SILVA, 2013, p. 3I), "não há um único jeito de se fazer as coisas [...]. Num mundo em transição na crise do paradigma das certezas absolutas, na emergência do novo, não há, realmente, um único jeito de se fazer as coisas. 
Entendendo a educação inclusiva como um "novo" paradigma educacional, sua efetivação promove nos educadores uma postura transformadora, ressignificando e criando práticas pedagógicas que contemplem a diversidade do corpo discente presente na escola contemporânea. Nesse sentido, entendemos a avaliação como uma estratégia a ser construída ou reconfigurada no âmbito da proposta didática curricular.

Nesse processo, tornam-se imprescindíveis dois tipos de vínculos: Primeiro, o contexto no qual se produz a avaliação, ou seja, o desempenho do aluno a ser avaliado é singular e produzido de acordo com determinadas condições que lhe são concedidas. E segundo, esse desempenho não diz respeito apenas ao sujeito avaliado, mas expressa, em sua configuração, as crenças e suposições daquele que o avalia (VASCONCELOS, 20I4; ESTEF, 202I).

A avaliação não pode ser uma prática isolada e segmentada; ela compõe a trama escolar, e se emaranha nos discursos produzidos sobre o aluno. Deixa de ser um instrumento classificatório e adquire um caráter pedagógico na medida em que serve de base para a produção ou revisão de estratégias facilitadoras da aprendizagem de todos os estudantes, sobretudo os que apresentam necessidades educacionais especiais. Os instrumentos e procedimentos avaliativos, assim, são construídos visando direcionar a continuidade do processo de ensino e aprendizagem. Ou seja, refletir se os métodos de ensino adotados atenderam à demanda educacional daquele aluno ou se há necessidade de modificar as estratégias. Com este enfoque, a avaliação torna-se o fio condutor que une todas as práticas escolares. Nesta mesma direção, planejamento e avaliação deixam de ser concebidos como etapas sequenciais do processo didático, passando a integrar um mesmo movimento que tende se retroalimentar (ESTEF, 202I).

Esta configuração do processo de avaliação implica em ultrapassar as fronteiras epistemológicas que sustentam o pensamento tradicional sobre ensinar, aprender, mediar. Enfim, trata-se de uma transformação radical na organização e cultura escolar (GLAT; PLETSCH, 20I I). Nesta perspectiva, o erro deixa de ser uma "falha" do aluno, tornando-se hipótese que, se ressignificada, pode abrir o caminho para sua aprendizagem. Em outras palavras, "os erros dos alunos são uma indicação de que nossos métodos de ensino são inadequados, e que devem ser modificados" (SIDMAN; STODDARD, 1966; apud KADLEK; GLAT, 1989, p. 135). 


\section{Considerações finais}

A implementação da política de educação inclusiva, com a abertura das escolas comuns para um público até então restrito ao ensino especial, trouxe, como exaustivamente apontado, a necessidade de transformar um modelo educacional fundado numa concepção homogeneizadora do processo ensino aprendizagem (GLAT; NOGUEIRA, 2002) em uma estrutura pedagógica curricular que considere a diversidade do alunado.

Para além de ações que garantam acessibilidade aos espaços, recursos e às próprias práticas pedagógicas, talvez o maior desafio que a escola contemporânea se depare seja o processo de avaliação do desempenho escolar. Ou seja, conciliar um sistema seriado com diretrizes curriculares prédeterminadas a serem cumpridas a cada etapa de escolarização, com as demandas de estudantes com significativas diferenças de desenvolvimento e aprendizagem.

Entretanto, apesar das dificuldades e contradições inerentes a um momento de transição paradigmática, as escolas vêm assumindo novas perspectivas de ensino e avaliação, com base em procedimentos de flexibilização e individualização. Partindo de experiencias e concepções de professores e coordenadores pedagógicos, o presente artigo teve como objetivo discutir possibilidades de reconfiguração de critérios e práticas avaliativas que tornem esse processo, mais do que um aferidor do conhecimento adquirido, um instrumento diagnóstico para aprimorar a aprendizagem de alunos com necessidades educacionais especiais.

Não resta dúvida de que a avaliação da aprendizagem é um dos pontos mais controversos do sistema escolar. Sobretudo no se refere à inclusão de alunos com deficiências em turmas comuns, é um aspecto que ainda não está totalmente equacionado.

Entretanto, como não há mais espaço na contemporaneidade para uma escola seletiva e excludente, as instituições educacionais têm sido impulsionadas a rever suas propostas curriculares e práticas pedagógicas, o que reflete, diretamente, no processo de avaliação. Na busca por uma escola inclusiva, os educadores são provocados a ressignificar sua atuação e desenvolver ações que rompam com o caráter controlador e classificatório da avaliação, produzindo caminhos mais reflexivos e dialógicos, que favoreçam o processo de escolarização de todos os alunos.

Olhar de professor, Ponta Grossa, v. 24, p. I-13, e-19708.096, 2021.

Disponível em <https://revistas2.uepg.br/index.php/olhardeprofessor> 


\section{Referências}

BRASIL. Secretaria de Educação Fundamental. Parâmetros curriculares nacionais: introdução aos parâmetros curriculares nacionais. Brasília: MEC/SEF, 1997.

BRASIL. Política Nacional de Educação Especial na Perspectiva da Educação Inclusiva. Brasília: MEC/SEESP, 2008.

BRASIL. Ministério da Educação. Secretaria de Educação Especial. Conselho Nacional de Educação/Câmara de Educação Básica. Resolução $\mathbf{N}^{\mathbf{0} 4}$, de 02 de outubro de 2009. Institui as diretrizes operacionais para $\circ$ atendimento educacional especializado na Educação Básica - na modalidade Educação Especial. 2009.

BRASIL. Decreto $\mathbf{N}^{\circ} \mathbf{7 . 6} \mathrm{I}$, de 17 de novembro de 20II. Dispõe sobre a educação especial, o atendimento educacional especializado e dá outras providências. 201 la.

BRASIL. Decreto $\mathbf{N}^{\circ}$ 7.6 I 2, de 17 de novembro de 20II. Institui o Plano Nacional dos Direitos da Pessoa com Deficiência - Plano Viver sem Limite, $20 \mathrm{I}$ lb.

BRASIL. Lei Brasileira de Inclusão da Pessoa com Deficiência/Estatuto da Pessoa com Deficiência, Lei 13.146, promulgada em 06/07/20I5. Brasília, 2015.

BRASIL. INEP Censo da Educação Básica 2020: resumo técnico. Brasília, 2020. in: https://download.inep.gov.br/publicacoes/institucionais/estatisticas_e_indicadores/resumo_tecnico _censo_escolar_2020.pdf,2020.

CANEN, A. Avaliação da aprendizagem e regulação da prática docente: formação continuada para coordenadores pedagógicos - Módulo 7. UFRJ.Rio de Janeiro, 2005.

CARVALHO, R. E. Escola inclusiva: a reorganização do trabalho pedagógico. Porto Alegre: Mediação, 2008.

ESTEF, S. Concepções sobre os processos de avaliação escolar para alunos com necessidades educacionais especiais sob a ótica docente. 2016. 137f. Dissertação (Mestrado em Educação) - Faculdade de Educação, Universidade do Estado do Rio de Janeiro, Rio de Janeiro, 2016.

ESTEF, S. Inclusão escolar sob o viés da avaliação flexibilizada. 202I. I34f. Tese (Doutorado em Educação) - Faculdade de Educação, Universidade do Estado do Rio de Janeiro, Rio de Janeiro, 2021

GLAT, R.; NOGUEIRA, M. Políticas educacionais e a formação de professores para a educação inclusiva no Brasil. In: Revista Integração. v. 24, ano I4; Brasília: MEC/SEESP, p. 22- 27, 2002

GLAT, R.; PLETSCH, M. D. Inclusão escolar de alunos com necessidades especiais. Rio de Janeiro: Eduerj, 20II.

KADLEK, V. P.; GLAT, R. A criança e suas deficiências: métodos e práticas de atuação psicopedagógicas. 2a ed. Rio de Janeiro: Editora Agir, 1989. 
KASSAR, M. C. M.; REBELO, A. S.; OLIVEIRA, R. T. C. Embates e disputas na política nacional de Educação Especial brasileira. Educação e Pesquisa, São Paulo, v. 45, e 217170, 2019.

LUCKESI, C. C. Avaliação da aprendizagem escolar: estudos e proposições. São Paulo: Cortez, 1995.

MARIN, M.; MARETTI, M. Estratégia de ensino para inclusão escolar. I Seminário internacional de inclusão escolar: prática em diálogo. Universidade do Estado do Rio de Janeiro. CAP-UERJ. Rio de Janeiro. 2014.

MASCARO, C. A.; REDIG, A. G. Estudantes com deficiência intelectual na escola contemporânea: práticas pedagógicas exitosas. Revista Teias Seção temática Programas e práticas pedagógicas na educação especial e inclusiva. 22 • n. 66 • jul./set. 2021.

MATOS, N.; MENDES, E. G. A proposta de inclusão escolar no contexto nacional de implementação das políticas educacionais. Revista Práxis Educacional, Dossiê temático: Educação Inclusiva, v.10. n.16, p. 35-59, 2014.

OLIVEIRA, A. A. S. de.; VALENTIM, F. O. D.; SILVA, L. H. Avaliação pedagógica: Foco na deficiência intelectual numa perspectiva inclusiva. São Paulo: Cultura acadêmica/ Marília: Oficina Universitária, 2013.

ONU, Convenção sobre os Direitos das Pessoas com Deficiência. Organização das Nações Unidas, 2007.

PLETSCH, M. D.; OLIVEIRA, M. C. P. de. Políticas de Educação Inclusiva: considerações sobre a avaliação da aprendizagem de alunos com deficiência intelectual. Revista Educação, Artes e Inclusão, v. 10, n. 2, p. 125-137, 2014.

PLETSCH, M. D.; SOUZA, F. F. Educação comum ou especial? Análise das diretrizes políticas de educação especial brasileiras. Revista Ibero-Americana de Estudos em Educação, Araraquara, v. 16, n. esp. 2, p. I286-1306, maio 2021.https://doi.org/10.21723/riaee.v16iesp2.15I26

PERRENOUD, P. Avaliação: da excelência à regulação das aprendizagens. Porto Alegre: Artmed, 1999.

SANTOS, T. C. C.; MARTINS, L. de A. R. Práticas de Professores Frente ao Aluno com Deficiência Intelectual em Classe Regular. Revista Brasileira de Educação Especial, Marília, v.2I, n.3, p.395408, 2015.

TOMLINSON, C. A. Diferenciação pedagógica e diversidade. Ensino de alunos em turmas com diferentes níveis de capacidades. Porto Alegre, 2008.

UNESCO. Declaração de Salamanca e Linha de Ação sobre Necessidades Educativas Especiais. Brasília: CORDE, 1994. 
VASCONCELOS, C. Avaliação classificatória e excludente e a inversão fetichizada da função social da escola. In FERNANDES, Claúdia (Org.). Avaliação das aprendizagens: sua relação com o papel social da escola. São Paulo: Cortez, 2014. p. 17-56.

ZERBATO, A. P.; MENDES, E. G. Desenho Universal para Aprendizagem como estratégia de inclusão escolar. Educar- Unisinos, 22(2), p. I47-I55, abril-junho, 2018.

Recebido em: 17 de outubro de 2021.

Versão corrigida recebida em: 27 de novembro de 202I

Aceito em: 27 de novembro de 2021 .

Publicado online em: 22 de dezembro de 2021. 